\title{
Nematóides das galhas, Meloidogyne spp., associadas ao parasitismo de plantas na Regiāo Amazônica. II-No Estado do Pará
}

\author{
Francisco das Chagas Oliveira Freire $(")$ \\ Terezinha de Almeida Freire $\left(^{* t}\right)$
}

\section{Resumo}

Prosseguindo o levantamento das plantas hospedeiras dos nematóides das galhas, Meloidogyne spp. em municípios do Estado do Pará, 47 diferentes espécies hospedeiras, dentre plantas cultivadas e silvestres foram catalogadas. Do total de plantas alistadas, 21 não haviam sido ainda, ao que consta, registradas como hospedeiras dos mencionados parasitas. Três espécies de nematóides das galhas foram identificadas no curso deste levantamento.

\section{INTRODUÇÃo}

A ampla dispersão geográfica alcançada pelos nematóides do gênero Meloidogyne Goeldi, 1887, nas diversas regiões agrícolas do mundo, a par de sua elevada capacidade de parasitismo, asseguram aos referidos organismos uma situação destacada dentre os inúmeros fitopatógenos já conhecidos.

Desenvolvendo-se satisfatoriamente em regiōes tropicais os nematóides das galhas podem ocasionar graves e freqũentes danos à agricultura.

O trabalho em apreço tem por objetivo o reconhecimento das plantas hospedeiras e espécies de nematóides das galhas ocorrentes na região amazônica.

\section{MATERIAL E MÉTODOS}

A coleta e preservação das amostras examinadas, bem assim a identificação das espécies de nematóides envolvidas no parasitismo, processaram-se de acordo com Freire (1976)

Todo o material coletado e preservado em formalina a $5 \%$ foi incorporado à Coleção Nematológica do Centro de Pesquisa Agropecuária do Trópico Úmido (CPATU) - EMBRAPA, em Belém (Pará).

\section{RESULTADOS E DISCUSSÃO}

Representando uma segunda etapa do trabalho, o levantamento em apreço possibilitou a catalogação de 47 diferentes plantas hospedeiras dos nematóides das galhas, nos diversos municípios amostrados.

As plantas catalogadas, além das espécies de Meloidogyne identificadas, encontram-se relacionadas no Quadro I.

A espécie $M$. incognita foi identificada em $87 \%$ das plantas catalogadas, confirmando, à semelhança da primeira etapa, uma maior dispersão que as demais. A segunda espécie em freqüência foi $M$. javanica, a qual foi reconhecida em $32 \%$ dos hospedeiros, enquanto $M$. arenaria esteve presente em uma única oportunidade. Apenas um dentre os materiais coligidos não permıtiu a identificação da espécie envolvida no parasitismo. Com efeito, o precário estado das raízes de Indigofera endecaphylla e das fêmeas adultas do nematóide, impediram a confirmação da espécie do parasita. Estes resultados, em termos de freqüência, assemelham-se aos já obtidos por Lordello (1964) em São Paulo, Ponte (1968) no Ceará, Freire \& Ponte (1976) na Bahia e Freire (1976) no Pará.

A lista ora divulgada apresenta vários destaques interessantes, tanto no que concerne à inclusão de plantas de expressão econômica, como pelo ingresso, na literatura nematológica, de novos hospedeiros. De acordo com os catálogos elaborados por Goodey, Franklin \& Hooper (1965) e Ponte (1977), um total de 21 plantas, dentre as 47 alistadas, não foram ainda referidas como hospedeiras dos nematóides das galhas. Assim, Axonopus pubivaginatus, Byrsonima spicata (muruci-vermeIho), Commelina longicalis (maria-mole), Cor-

(*) - Centro de Pesquisa Agropecuária do Trópico Úmido, Belém.

(**) - Estagiária junto ao Laboratório de Fitopatologia do CPATU-EMBRAPA, Belém. 
QUADRO I - Relação das plantas hospedeiras dos nematóides das galhas, Meloídogyne spp., catalogadas no Estado do Pará.

\begin{tabular}{|c|c|c|c|c|c|}
\hline \multirow{2}{*}{ Nome vulgar } & Hospedeiros & \multicolumn{4}{|c|}{ Meloidogyne } \\
\hline & Nome cientifico & Mi & $\mathbf{M j}$ & Ma & Msp. \\
\hline
\end{tabular}

Abieiro

Agrião-do-brejo

Algodão-do-préa

Amendoim-rana

Anil

Biribazeiro

Bucha

Caiçara

Camembecá

Caru-caá

Castanha-do-Pará

Caupi

Chanana

Chicória

Crista-de-galo

Douradinha

Erva-moura

Erva tapete

Favaca-rana

Feijão-alado

Feijäo-comum

Gambir

Mamoeiro

Maracujazeiro

Maria-mole

Mentrasto

Muruci-vermelho

Perpétua-do-mato

Piāo-rana

Quebra-pedra branco

Trevo-cumaru

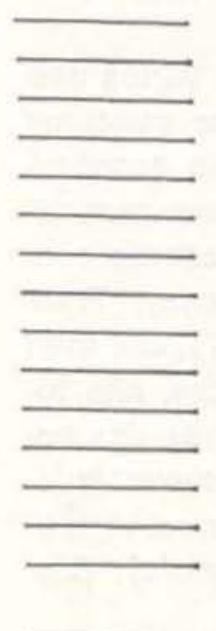

Pouteria caimito (R, Et. P.) Radlk.

Eclipta alba (L.) Hassk.

Emilia sanchifolia (L.) DC.

Indigofera hirsuta $\mathrm{L}$.

Indigofera endecaphylla Jacq.

Rollinia orthopetala DC.

Luffa cylindrica $R$. Roem.

Solanum auriculatum Ait.

Polygala mollis L.

Cordia multispicata Cham.

Bertholletia excelsa H.B.K.

Vigna sinensis (L.) Savi

Turnera ulmifolia $\mathrm{L}$,

Cichorium endivia L.

Celosia cristata Moq.

Lindernia sp.

Solanum nigrum $\mathrm{L}$.

Mollugo verticillata $L$.

Monnieria trifolia L,

Psophocarpus tetragonolobus (L.) DC

Phaseolus vulgaris $L$.

Uncaria gambier Roxb.

Carica papaya $L$.

Passiflora edulis L.

Commelina longicaulis Jacq.

Ageratum conyzoides $\mathrm{L}$.

Byrsonima spicata (Cav.) H.B.K.

Borreria latifolia (Aubl.) K. Schum

Croton lobatus L.

Phyllanthus urinaria $\mathrm{L}$.

Justicia pectoralis Jacq.

Axonopus pubivaginatus Hur.

Cannabis sativa $\mathrm{L}$.

Cassia mimosoides L.

Croton miquelensis Ferguson

Cyperus compressus L.

Cyperus flavus (Vahl.) Nees

Cyperus sphacelatus Rottb.

Cyperus surinamensis Rottb.

Cyperus sp.

Digitaria horizontalis Willd.

Eragrostis amabilis (L.) Wight

Eragrostis ciliaris (L.) Link.

Erechtides hieracifolia (L.) Rafin

Fimbristylis annua M. Rcem. \& Schult.

Hemicarpha micrantha (Vahl.) Britton var.

minor (Schrad.) Friedland,

Paspalum decumbens Swartz. $\mathrm{x}$

$\mathrm{x}$

$x$

$\mathrm{x}$

$\mathrm{x}$

X

$x$

$x$

$x$

$x$

$x$ 
dia multispicata (caru-caá), Croton miquelensis, Cyperus flavus, Cyperus sphacelatus, Cyperus surinamensis, Digitaria horizontalis, Eragrostis amabilis, Fimbristylis annua, Hemicarpha micrantha var. minor, Justicia pectoralis (trevo-cumaru), Lindernia sp. (douradinha), Monnieria trifolia (favaca-rana), Paspalum decumbens, Phyllanthus urinaria (quebra-pedra branco), Polygala mollis (camembecá), Pouteria caimito (abieiro), Rollinia orthopetala (biribazeiro) e Uncaria gambier (gambir) incluem-se agora como os mais recentes hospedeiros dos vermes em questão. Acresça-se ainda, a ocorrência de Borreria latifolia (perpetua-do-mato), a qual, embora já referida como hospedeira de $M$. incognita, é agora, pela primeira vez, relacionada como hospedeira da espécie $M$. javanica. A exceção de Bertholletia excelsa (castanha-do-Pará), já citada por Freire \& Ponte (1976) como hospedeira de $M$. incognita no Estado do Pará, todas as demais plantas alistadas no Quadro I são, pela primeira vez, assinaladas como hospedeiras destas três espécies de nematóides na região amazônica .

A exemplo da primeira etapa do levantamento, esta segunda fase evidencia a ocorrência de espécies de nematóides das galhas associadas ao parasitismo de diversas culturas de interesse econômico para a amazônia. Verifica-se, ademais, uma acentuada freqüência de parasitismo em plantas silvestres, as quais podem atuar como hospedeiros alternativos para os nematóides das galhas, permitindo um crescente aumento da população nêmica ativa nas raizes e solo.

\section{CONCLUSÕES}

A segunda etapa do levantamento de plantas hospedeiras e espécies dos nematóides das galhas ocorrentes na região amazônica permite as conclusões seguintes:

a - A grande dispersão alcançada pelos nematóides do gênero Meloidogyne Goeldi, 1887. aliada à expressão agrícola de muitas das plantas catalogadas como hospedeiras de suas espécies, acentuam a importância econômica do seu parasitismo para a regiảo amazônica; b - Dentre as três espécies de Meloidogyne assinaladas durante esta etapa do levantamen- to, $M$. incognita exibiu a maior freqüência de parasitismo, estando associada a $87 \%$ das plantas catalogadas. A segunda espécie mais freqüente foi $M$. javanica, com um percentual de parasitismo da ordem de $32 \%$, enquanto $M$. arenaria foi identificada em uma única oportunidade;

c - Das 47 plantas catalogadas como hospe. deiras dos nematóides das galhas, 21 são registradas pela primeira vez como tal. A par da ocorrência de um elevado número de plantas silvestres hospedeiras dos referidos vermes há de se considerar, principalmente, a expressão agrícola de inúmeras plantas catalogadas na oportunidade.

\section{AGRADECIMENTOS}

Ao Paulo Roberto Pinheiro Bouças, funcionário do Setor de Botânica do Centro de Pesquisa Agropecuária do Trópico Úmido (CPATU) - EMBRAPA, pela inestimável colaboração na identificação das plantas coligidas.

\section{SUMMARY}

As a result of a survey carried out in the State of Para, Brazil, forty-seven different species of wild and cultivated plants were identified as hosts of the root-knot nematodes Meloidogyne spp, Twenty-one of these plants are new host records of the root-knot nematodes.

Three species of root-knot nematodes were found in this survey: M. incognita (Kofoid \& White, 1919) Chitwood, 1949. M. javanica (Treub, 1885) Chitwood, 1949 and M. arenaria (Neal, 1889) Chitwood, 1949.

\section{BIBLIOGRAFIA CITADA}

FREIRE, F.C.O.

1976 - Nematóides das galhas, Meloidogyne spp., associados ao parasitismo de plantas na região amazônica - I - no Estado do Pará. Acta Amazonica, 6(4): 405-408.

Freire, F.C.O. \& PONTE, J.J. DA

1976 - Nematóides das galhas, Meloidogyne spp., associados ao parasitismo de plan. tas no Estado da Bahia (Brasil). Bol. Cear. Agron., 17: 47-55.

GOOdey, J.B.; FrANkLiN, M.T. \& HoOper, D.J.

1965 - The nematodes parasites of plants catalogued under their hosts. Commow. Agric. Bur., Farnham Royal, 214 p. 
LORDELLO, L.G.E.

1964 - Contribuição ao conhecimento dos nematóides que causam galhas em raízes de plantas em Sãc Paulo e Estados vizinhos An. Esc. Sup. Agric., "Luiz de Queiroz", 21 : 181-218.

PONTE, J.J. DA

1968 - Subsídios ao conhecimento de plantas hospedeiras e ao controle dos nematóides das galhas. Meloidogyne spp., no
Estado do Ceará (Tese de M.S.). Bol. Cear. Agron., 9:1-26.

1977 - Nematóides das galhas - Espécies ocorrentes no Brasil e seus hospedeiros (Tese de Livre Docência) Centro de Ciências Agrárias, U.F.C., 124 p.

(Aceito para publicação em $31 / 08 / 78$ ) 